\title{
Etorkizuna Eraikiz a cross-cutting collaborative experience for innovative policies and services in Gipuzkoa
}

\author{
Igone Guerra \\ Sinnergiak Social Innovation, University of the Basque Country \\ iguerra@sinnergiak.org \\ Xabier Barandiarán \\ University of Deusto \\ xabier.barandiaran@deusto.es
}

\begin{abstract}
Western societies are increasingly complex. Globalization as well as the irruption of the Technologies of Information and Communication (TICs) are resulting in great transformation within the current economic, political and social systems. The financial and economic crisis we have faced since 2008 has exposed the inability of the governmental institutions to solve the challenges of the society. This has meant both a great disengagement of the citizenry from the politics and also a loss of confidence in the institutional system, and more specifically, in the public (political parties as well as public administration). In this context, citizens now are demanding innovative solutions to tackle emerging "wicked problems". These solutions are presenting in the form of new ways of practicing politics and making policies, in which the participation of the stakeholders (including the citizenry) in the decision making-process is mandatory. In short, these transformations are demanding a new paradigm shift that moves away from the old public administration to a new way of collaborative governance. In Gipuzkoa (The Basque Country), the local government, aware of this new reality, has been promoting since 2015 a new initiative, called Etorkizuna Eraikiz (Building the Future), that aims at laying down an innovative political culture in the territory. In this contemporary initiative, deliberation and collaboration are prominent strategies to recover trust in institutions.
\end{abstract}

Keywords: citizen participation, co-creation, meta-governance, public sector innovation, trust 